\title{
Fostering Representational Flexibility in the Mathematical Working Space of Rational Numbers
}

\author{
Favorecer la Flexibilidad Representacional en el Espacio de Trabajo \\ Matemático de los Números Racionales
}

\author{
Athanasios Gagatsis* \\ Eleni Deliyianni** $^{* *}$ \\ Iliada Elia ${ }^{* * *}$ \\ Areti Panaoura ${ }^{* * * *}$ \\ Paraskevi Michael-Chrysanthou ${ }^{* * * *}$
}

\begin{abstract}
The study focuses on the cognitive level of Mathematical Working Space (MWS) and the component of the epistemological level related to semiotic representations in two mathematical domains of rational numbers: fraction and decimal number addition. Within this scope, it aims to explore how representational flexibility develops over time. A similar developmental pattern of four distinct hierarchical levels of student representational flexibility in both domains is identified. The findings indicate that the genesis of the semiotic axis in fraction and decimal addition is not automatic, but a long process of developmental steps that could be referred to as MWS1, MWS2, MWS3, MWS4 (final). There is not a clear and stable correspondence between developmental levels of representational flexibility and school grades. Didactical implications in order to foster representational flexibility in the MWS of fraction and decimal addition are discussed.
\end{abstract}

Key words: Representational Flexibility. Mathematical Working Space. Fractions. Decimals.

\section{Resumen}

El estudio se centra en el nivel cognitivo del Espacio de Trabajo Matemático (ETM) y en el plano epistemológico relacionado con las representaciones semióticas en dos dominios matemáticos de números racionales: fracción y número decimal. Dentro de este ámbito, se pretende explorar cómo la flexibilidad representacional evoluciona en el tiempo. Se identificó un patrón de similar de desarrollo de flexibilidad de representación en los en ambos dominios.. Los resultados indican que la génesis semiótica en la fracción y la adición decimal no es automática, sino un largo proceso de pasos de desarrollo que podría denominarse como ETM1, ETM2, ETM3, ETM4. Sin embargo, no hay una correspondencia clara y estable entre los niveles de

"Ph.D., University of Cyprus (UCY),Nicosia, Cyprus, University House "Anastasios G. Leventis", 1 Panepistimiou Avenue, Aglantzia,Nicosia, P.O. Box 20537, gagatsis@ucy.ac.cy

*** Ph.D., University of Cyprus (UCY), Cyprus Pedagogical Institute, Nicosia, Cyprus, 40 Macedonia Avenue, 2238 Latsia, P.O.Box 12720, 2252, sepged1@ucy.ac.cy

${ }^{* * *}$ Ph.D., University of Cyprus (UCY),Nicosia, Cyprus,P.O.Box 20537, 1678, elia.iliada@ucy.ac.cy

${ }^{* * * *}$ Ph.D., University of Cyprus (UCY), Frederick University,Nicosia, Cyprus, 7, Y. Frederickou Str. Pallouriotisa, 1036, pre.pm@frederick.ac.cy

${ }_{* * * * * *}$ Ph.D., University of Cyprus (UCY), Nicosia, Cyprus, P.O.Box 20537, 1678, pmicha@ucy.ac.cy 
desarrollo de la flexibilidad y los cursos escolares. Se discuten las implicaciones didácticas con el fin de fomentar la flexibilidad de representación en las MWS de fracción y la adición decimal.

Palabras clave: Flexibilidad Representacional. Espacio de Trabajo Matemático. Fracciones. Decimales.

\section{Introduction}

Mathematical work is the result of a continuous process of genesis that allows an inner joint at epistemological and cognitive level and the articulation of these two levels. The first one, the epistemological, is in close relation with the mathematical content of the study's area, and the other the cognitive, related to the thinking of the person solving mathematical tasks (KUZNIAK, 2011). The three fundamental geneses, the instrumental, the semiotic and the discursive, are independent and concern all epistemological components and cognitive processes (KUZNIAK; RICHARD, 2014). The present study related to the semiotic genesis based namely as Kuzniak and Richard (2014) indicated on the registers of the semiotic representation which gives meaning to the Mathematical Working Space (MWS) objects and confers to them their status of operative mathematical objects. This semiotic genesis ensures the relationships between syntax, semantics, functions and structure of the conveyed signs.

We take into consideration that the mathematical work at school can take place at three levels: personal, reference and adequate MWS. Mathematics aimed at by the institutions is described in the reference MWS. This should be arranged by the teacher in an adequate MWS, in order to allow effective implementation in the classroom where each student works within his personal MWS (KUZNIAK, 2015). Our study aims to explore how representational flexibility develops over time. Further knowledge about a possible developmental trend in students' representational flexibility in fraction and decimal number addition can provide improved clarity about the students' individual differences in flexible mathematical thinking. Knowledge of this developmental progression may contribute to the designing of learning and assessment activities that stimulate the cognitive processes which move students through levels of flexible thinking in the particular domain. The importance of this study is even more emphasized taking into account that the curriculum devotes a lot of time to work with fractions and decimals, but both teachers and students find the ideas and skills related with these numbers difficult (BARNETT-CLARKE; FISHER; MARKS; ROSS, 2010). In fact, Fandiño Pinilla (2007) indicated that the teaching and learning process regarding fractions (and decimals) is certainly one of the most studied since the beginning of research into 
Mathematics Education, probably because it represents one of the most evident areas of failure at schools all over the world.

\section{Theoretical framework}

Mathematical activity evolves through two types of transformations of semiotic representations: treatments and conversions. Treatments are transformations of representations that happen within the same system of representation e.g., carrying out a calculation while remaining strictly in the same notation system for representing numbers. Conversions are transformations of representation that consist of changing a system of representation without changing the objects being denoted e.g., passing from the algebraic notation for an equation to its graphic representation. Conversion is more complex than treatment because any change of representation system first requires recognition of the same represented object between two representations whose contents have often nothing in common (DUVAL, 2006). Besides treatment and conversion, recognizing the same mathematical concept in multiple representations is considered essential for the acquisition of the concept (LESH; POST; BEHR, 1987).

Following the aforementioned theoretical positions, recently Deliyianni, Gagatsis, Elia, and Panaoura (2015) refer to representational flexibility as the ability to handle withinrepresentation transformations (intra-representation flexibility) and between-representation transformations (inter-representation flexibility) of the same mathematical object. Treatment competence refers to intra-representation flexibility, as the transformations it requires take place within the same representation. Recognition and conversion competences refer to interrepresentation flexibility, as they both involve changing a representation. However, conversion involves the construction of the target representation standing for the same object that is denoted in the initial representation, while recognition does not.

A number of studies stress the necessity of using a variety of appropriate representations in supporting and assessing student constructions of fractions (e.g. LAMON, 2001) and decimals (e.g. IRWIN, 2001; IUCULANO; BUTTERWORTH, 2011; RODITI, 2007). According to Deliyianni et al. (2015) the flexibility in multiple representations of fraction addition constitutes a multifaceted construct in which there is an interaction of the different types of representation transformations (recognition, treatment, and conversion) with the modes of representations (symbolic and diagrammatic) and the complexity of the concept 
involved (summands' denominators). Similarly, the flexibility in multiple decimal number addition representations involves an interaction between representation transformations, the modes of representation, and the place-value concept. In particular, the competences which Deliyianni et al. (2015) suggest that compose representational flexibility in fraction addition are the following: same denominator fraction-addition recognition, different denominator fraction-addition recognition, treatment of symbolic representations, conversion from a symbolic to a diagrammatic representation and conversion from a diagrammatic to a symbolic representation. Similarly, the competences that consist representational flexibility in decimal number addition are the recognition with the same number of decimal digits, the recognition with different number of decimal digits, the treatment of symbolic representations, the conversion from a symbolic to a diagrammatic representation and the conversion from a diagrammatic to a symbolic representation (DELIYIANNI et al., 2015).

\section{Methodology}

The study is conducted among 1701 students, aged 10 to 14, of primary and secondary schools in Cyprus (414 at Grade 5, 415 at Grade 6, 406 at Grade 7, 466 at Grade 8). A test was administered to the students by their teachers at the end of the school year in usual classroom conditions. The teachers were instructed that students must work on their own and no assistance should be given to them. All students had already received teaching by their teachers on the concepts of fraction and decimal number, fraction equivalence, fraction and decimal number order, same and different denominator fraction addition and decimal number addition in which the summands consist of tenths and/ or hundreds before the study.

The test included: (a) 17 representational flexibility tasks in fraction addition and (b) 19 representational flexibility in decimal number addition. Representational flexibility tasks differed in terms of the following three aspects: (a) the transformations of representations, b) the types of representation and c) the rational number concept. With respect to the transformations, there were three types of tasks: recognition (Type Re tasks), treatment (Type Tr tasks) and conversion (Type Co tasks) tasks. Concerning the types of representation, both diagrammatic and symbolic representations were involved. The diagrammatic representations that were used are the rectangular area, the circular area and the number line. We concentrated on circular and linear model since they are the two types of geometric shapes that are used to introduce the continuous model of fractions (BOULET, 1998). The part-whole whole 
subcontract of rational numbers is used, which is consider fundamental for developing understanding of fractions as ratio, operator, quotient and measure (LAMON, 2001). The measure subcontract that is involved in tasks of number line is regarded as helpful for reaching additive operations with rational numbers (CHARALAMBOUS; PITTA-PANTAZI, 2007).

Table 1- The Representational Flexibility Processes in Fraction Tasks

\begin{tabular}{lllll}
\hline Competence & Denominators & Representation/s & Diagram & Variables \\
\hline Recognition & Same & Symbolic to diagrammatic & Number line & Ref1 \\
& & & Circle & Ref2 \\
& & & Rectangle & Ref3 \\
& \multirow{2}{*}{ Different } & Symbolic to diagrammatic & Circle & Ref4 \\
& & & Rectangle & Ref6 \\
& & & Number line & Ref7 \\
\hline Treatment & Same & Symbolic & & Trf8 \\
& Different & & & Trf9 \\
& & & & Trf10 \\
\hline Conversion & Same & Symbolic to diagrammatic & Circle & Cof11 \\
& & & Number line & Cof12 \\
& Different & & Rectangle & Cof13 \\
& Same & Diagrammatic to symbolic & Number line & Cof14 \\
& & & Circle & Cof15 \\
& Different & & Number line & Cof16 \\
& & & Rectangle & Cof17 \\
\hline
\end{tabular}

Table 2- The Representational Flexibility Processes in Decimal Tasks

\begin{tabular}{lllll}
\hline Competence & Decimal places & Representation/s & Diagram & Variables \\
\hline Recognition & Same number & Symbolic to diagrammatic & Circle & Red1 \\
& & & Number line & Red2 \\
& & & Rectangle & Red3 \\
& & Circle & Red4 \\
& & & Number line & Red5 \\
& & & Rectangle & Red6 \\
& Different number & Symbolic to diagrammatic & Circle & Red7 \\
& & & Number line & Red8 \\
\hline Treatment & Same number & Symbolic & Rectangle & Red9 \\
& & & & Trd10 \\
& & & & Trd11 \\
& & & & Trd13 \\
Conversion & Same number & Symbolic to diagrammatic & Rectangle & Cod16 \\
& & & Circle & Cod17 \\
& Different number & & Number line & Cod15 \\
& Same number & Diagrammatic to symbolic & Rectangle & Cod18 \\
& & & Circle & Cod20 \\
& & & Number line & Cod19 \\
\hline
\end{tabular}


As for the rational number concept, distinction was made between the fractionaddition tasks (Type $\mathrm{f}$ tasks) and the decimal number addition tasks (Type $\mathrm{d}$ tasks). Both same and different denominator fraction additions and decimal number additions with the same and different number of decimal digits were included in the test. In recognition tasks, the students have to recognize whether the shaded part of a diagram corresponds to the symbolic expression of an addition of fractions or decimals. In treatment tasks, the students find an answer to the addition of fractions or decimals. In conversion from a symbolic to diagrammatic representation, students illustrate an addition of fractions or decimals. Examples of tasks used are shown in the Appendix. The conceptualization of the various processes that are involved in the tasks appears in Tables 1 and 2. The data were analyzed using quantitative methods (cluster analysis, ANOVA).

\section{Results}

To identify the student response profiles for representational flexibility in fraction and decimal addition, the Ward's method of hierarchical clustering was applied. The z-scores of the factors composing representational flexibility, based on the elaborated structural models presented in Deliyianni et al. (2015) were used as variables for clustering.

Four clusters were identified in the two mathematical concepts. The representational flexibility scores of the students in Clusters 1, 2, 3 and 4 are 0.25, 0.43, 0.55 and 0.79, respectively in fraction addition. In decimal number addition, the scores in Clusters 1, 2, 3 and 4 are $0.34,0.46,0.66$ and 0.75 , respectively. Analysis of variance (ANOVA) with the representational flexibility score as the dependent variable and the cluster as the independent variable showed that the differences in the representational flexibility scores among the four clusters were significant both in fraction $[\mathrm{F}(3,1697)=1009.46, \mathrm{p}<0.01]$ and decimal number addition $[\mathrm{F}(3,1697)=1274.21, \mathrm{p}<0.01]$. This suggests that there is a developmental pattern relative to representational flexibility in fraction and decimal number addition and that the four clusters may correspond to four distinct hierarchical levels of flexibility.

Table 3 and 4 present the mean scores and standard deviations on the representational flexibility components by cluster as suggested in Deliyianni et al. (2015) in fraction and decimal number addition, respectively. More specific information about the clusters' characteristics is provided in Table 5 and 6, which show the success percentages per representational flexibility task for the four clusters separately in fraction and decimal number 
addition respectively. This information allows us to indicate differences between diagrammatic representations (number line, bi-dimensional diagrams) and the complexity of fraction and decimal number addition (same/different denominators, same/different number of decimal digits). Students' characteristics in each cluster are presented in the following subsections.

Table 3 - Mean Scores and Standard Deviations in Representational Flexibility Components by Cluster in Fraction Addition

\begin{tabular}{|c|c|c|c|c|c|c|c|c|}
\hline Representational $\quad$ Flexibility & Clus & & Clus & & Clus & & Cluste & \\
\hline & Mea & & Meal & & Mea & & Mean & SD \\
\hline Same denominator fraction- & 0.37 & 0.30 & 0.44 & 0.31 & 0.52 & 0.32 & 0.71 & 0.27 \\
\hline $\begin{array}{l}\text { Different denominator } \\
\text { fraction-addition recognition }\end{array}$ & 0.20 & 0.31 & 0.04 & 0.11 & 0.77 & 0.16 & 0.83 & 0.17 \\
\hline Treatment & 0.24 & 0.16 & 0.87 & 0.20 & 0.87 & 0.23 & 0.91 & 0.20 \\
\hline $\begin{array}{l}\text { Conversion from symbols to a } \\
\text { diagram }\end{array}$ & 0.27 & 0.25 & 0.47 & 0.35 & 0.30 & 0.26 & 0.90 & 0.16 \\
\hline $\begin{array}{l}\text { Conversion from a diagram to } \\
\text { symbols }\end{array}$ & 0.14 & 0.24 & 0.29 & 0.32 & 0.33 & 0.32 & 0.62 & 0.35 \\
\hline $\mathrm{N}$ & 249 & & 331 & & 538 & & 583 & \\
\hline
\end{tabular}

Table 4 - Mean Scores and Standard Deviations in Representational Flexibility Components by Cluster in Decimal Addition

\begin{tabular}{|c|c|c|c|c|c|c|c|c|}
\hline $\begin{array}{ll}\text { Representational } & \text { Flexibility } \\
\text { Components }\end{array}$ & \multicolumn{2}{|c|}{ Cluster 1} & \multicolumn{2}{|c|}{ Cluster 2} & \multicolumn{2}{|c|}{ Cluster 3} & \multicolumn{2}{|c|}{ Cluster 4} \\
\hline & Mea & SD & Mean & SD & Mear & SD & Mean & SD \\
\hline $\begin{array}{l}\text { Recognition with the same } \\
\text { number of decimal digits }\end{array}$ & 0.50 & 0.28 & 0.54 & 0.24 & 0.76 & 0.23 & 0.78 & 0.19 \\
\hline $\begin{array}{l}\text { Recognition with different } \\
\text { number of decimal digits }\end{array}$ & 0.05 & 0.16 & 0.67 & 0.12 & 0.06 & 0.13 & 0.73 & 0.17 \\
\hline Treatment & 0.65 & 0.29 & 0.67 & 0.23 & 0.93 & 0.23 & 0.93 & 0.12 \\
\hline $\begin{array}{l}\text { Conversion from symbols to a } \\
\text { diagram }\end{array}$ & 0.36 & 0.28 & 0.31 & 0.25 & 0.74 & 0.29 & 0.69 & 0.29 \\
\hline $\begin{array}{l}\text { Conversion from a } \\
\text { diagram to symbols }\end{array}$ & 0.14 & 0.11 & 0.11 & 0.18 & 0.80 & 0.18 & 0.61 & 0.32 \\
\hline $\mathrm{N}$ & 530 & & 470 & & 179 & & 522 & \\
\hline
\end{tabular}


Table 5 - Percentages of Success in Representational Flexibility Tasks by Cluster in Fraction Addition

\begin{tabular}{|l|l|l|l|l|l|l|l|}
\hline Representational Flexibility Components & Tasks & $\begin{array}{l}\text { Total } \\
(\%)\end{array}$ & $\begin{array}{l}\text { Cluster 1 } \\
(\%)\end{array}$ & $\begin{array}{l}\text { Cluster 2 } \\
(\%)\end{array}$ & $\begin{array}{l}\text { Cluster 3 } \\
(\%)\end{array}$ & $\begin{array}{l}\text { Cluster } 4 \\
(\%)\end{array}$ \\
\hline $\begin{array}{l}\text { Same denominator fraction-addition } \\
\text { recognition }\end{array}$ & Ref1 & 61.4 & 35.4 & 48.6 & 55.6 & 84.9 \\
& Ref2 & 58.8 & 42.2 & 49.8 & 58.4 & 71.5 \\
& Ref3 & 69.7 & 56.2 & 61.9 & 68.4 & 81.0 \\
Different denominator fraction-addition & Ref4 & 31.2 & 13.3 & 19.3 & 26.6 & 49.9 \\
recognition & Ref5 & 45.6 & 13.7 & 4.5 & 58.6 & 70.5 \\
& Ref6 & 55.5 & 21.3 & 7.6 & 73.2 & 81.0 \\
Treatment & Ref7 & 68.4 & 24.9 & 0.6 & 98.0 & 98.3 \\
& Trf8 & 89.9 & 65.5 & 94.9 & 94.1 & 93.8 \\
Conversion from symbols to a diagram & Trf9 & 76.7 & 4.0 & 88.8 & 85.5 & 92.8 \\
& TrSd10 & 71.0 & 1.2 & 77.9 & 81.0 & 87.7 \\
Cof11 & 67.0 & 50.6 & 64.4 & 43.7 & 96.9 \\
& Cof12 & 52.3 & 26.1 & 49.2 & 26.8 & 88.7 \\
& Cof13 & 41.3 & 2.8 & 28.1 & 19.3 & 85.6 \\
& Cof14 & 35.7 & 11.6 & 25.4 & 27.0 & 60.0 \\
\hline
\end{tabular}

Table 6 - Percentages of Success in Representational Flexibility Tasks by Cluster in Decimal Addition

\begin{tabular}{|c|c|c|c|c|c|c|}
\hline Representational Flexibility Components & Tasks & $\begin{array}{l}\text { Total } \\
(\%)\end{array}$ & $\begin{array}{l}\text { Cluster } 1 \\
(\%)\end{array}$ & \begin{tabular}{|l|l|}
$\begin{array}{l}\text { Cluster } 2 \\
(\%)\end{array}$ \\
\end{tabular} & \begin{tabular}{|l|}
$\begin{array}{l}\text { Cluster } 3 \\
(\%)\end{array}$ \\
\end{tabular} & $\begin{array}{l}\text { Cluster } 4 \\
(\%)\end{array}$ \\
\hline \multirow{6}{*}{$\begin{array}{l}\text { Recognition with the same number of } \\
\text { decimal digits }\end{array}$} & Red1 & 55.4 & 47.5 & 51.3 & 75.4 & 60.2 \\
\hline & Red2 & 61.8 & 47.5 & 49.8 & 74.9 & 82.8 \\
\hline & Red3 & 64.8 & 50.2 & 59.6 & 77.7 & 79.5 \\
\hline & Red4 & 68.5 & 54.2 & 61.5 & 81.0 & 85.2 \\
\hline & Red5 & 44.2 & 35.5 & 31.5 & 60.9 & 58.8 \\
\hline & Red6 & 73.1 & 62.3 & 69.6 & 85.5 & 83.0 \\
\hline \multirow{3}{*}{$\begin{array}{l}\text { Recognition with different number of } \\
\text { decimal digits }\end{array}$} & Red7 & 45.3 & 6.8 & 66.2 & 10.1 & 77.8 \\
\hline & Red8 & 54.9 & 4.0 & 93.0 & 0.0 & 91.0 \\
\hline & Red9 & 29.5 & 4.9 & 43.0 & 7.3 & 50.0 \\
\hline \multirow[t]{5}{*}{ Treatment } & $\operatorname{Trd} 10$ & 95.3 & 90.2 & 94.9 & 99.4 & 99.4 \\
\hline & $\operatorname{Trd} 11$ & 92.1 & 84.2 & 91.3 & 97.8 & 98.9 \\
\hline & $\operatorname{Trd} 13$ & 62.4 & 42.5 & 43.8 & 89.9 & 89.8 \\
\hline & $\operatorname{Trd} 14$ & 75.4 & 63.2 & 64.7 & 91.5 & 91.8 \\
\hline & $\operatorname{Trd} 12$ & 59.8 & 44.0 & 39.1 & 84.9 & 85.8 \\
\hline \multirow[t]{3}{*}{ Conversion from symbols to a diagram } & Cod15 & 29.9 & 13.0 & 7.4 & 65.4 & 55.0 \\
\hline & Cod16 & 74.4 & 67.2 & 64.3 & 86.0 & 87.0 \\
\hline & Cod17 & 43.0 & 29.1 & 22.1 & 71.5 & 66.1 \\
\hline \multirow[t]{3}{*}{ Conversion from a diagram to symbols } & Cod18 & 49.0 & 27.9 & 23.0 & 94.4 & 78.2 \\
\hline & Cod19 & 30.7 & 9.6 & 7.2 & 74.9 & 58.2 \\
\hline & $\operatorname{Cod} 20$ & 23.6 & 3.6 & 3.2 & 69.3 & 46.7 \\
\hline $\mathrm{N}$ & & 530 & 470 & 179 & 522 & 530 \\
\hline
\end{tabular}




\subsection{Cluster 1}

The students in Cluster 1 for fraction addition show low performance in solving all types of representational flexibility tasks. From Table 3 it is evident that these students encounter greater difficulties in adding fractions with different denominators than with the same denominators irrespectively of the representational transformation required (recognition, treatment or conversion). To sum up, the students of Cluster 1 cannot respond adequately to any type of representational transformation and this poor performance is influenced by the complexity of fraction addition, that is, whether the addends had the same or different denominators. These characteristics led us to conclude that they belong to the lowest developmental level of representational flexibility, Level 1.

Students who belong to Cluster 1 for decimal numbers exhibit low performance in conversion tasks and tasks that involve recognition of decimal number addition with different number of decimal digits. However, they demonstrate moderate performance in treatment tasks. This characteristic may be related to decimal number similarities in notation with whole numbers. Their performance is also moderate in recognition tasks that involve recognition of decimal number addition with similar digits. According to Table 4, the students in Cluster 1 encounter greater difficulties in adding decimals with different number of decimal digits than with similar digits irrespective of the representational transformation required. They also have difficulties in treatment tasks Trd13 and Trd14 in which decimal digits are different between the addends and the sum. Their performance in tasks that demand understanding of the notion of equivalence in order to be solved is low even in adding decimals with similar digits (e.g. Cod17, Cod20). According to the results, the students in Cluster 1 have lower performance in conversion tasks from a diagrammatic to a symbolic representation in relation with the corresponding conversion tasks from a symbolic to a diagrammatic representation (Cod16Cod18, Cod17-Cod20, and Cod15-Cod19).

\subsection{Cluster 2}

Representational flexibility mean scores of students in Cluster 2 for fraction addition are higher than the scores of students in Cluster 1. The students in Cluster 2 demonstrate high performance in the symbolic treatment tasks. As in Cluster 1, the students in Cluster 2 perform much better in the same denominator fraction addition recognition tasks in relation to 
the recognition of different denominator fraction additions. They exhibit moderate performance in the conversion tasks from a symbolic to a diagrammatic representation. However, their performance in the conversions from a diagrammatic to symbolic representation is lower.

Two major dissociations appear in the performance of the students in Cluster 2 for fraction addition. First, although the students calculate fluently the sum of fractions with different denominators, they are not competent in recognizing whether a circle, a rectangle or a number line represented a given symbolic expression of fraction addition with different denominators. They also have great difficulties in converting fraction additions with different denominators from and towards symbolic expressions. These results suggest that, on the one hand, Cluster 2 students are able to apply an algorithmic procedure within the symbolic representation to add fractions with different denominators. On the other hand, their poor performance in the recognition and conversion tasks of fraction addition with different denominators indicate deficiencies in the understanding of essential concepts in this type of fraction addition, that is, fraction equivalence and part-whole relations. Cluster 2 students' weakness in fraction equivalence is further supported by their low performance in solving correctly the same denominator fraction addition recognition task in which the number of subdivisions on the number line was double the denominators of the symbolic expression (task Ref4). The second dissociation in the performance of Cluster 2 students is between the conversions from a symbolic expression to a diagram and the conversions from a diagram to a symbolic expression. In the former type of conversions they perform better in relation to the latter. This inconsistency in performance indicates that they do not sufficiently understand the common concept that both the symbolic expression and the diagrammatic representation denoted. Although students of Cluster 2 exhibit deficiencies in the recognition and conversion tasks, they succeed in treatment tasks; therefore, they belong to a higher level than Level 1, namely, Level 2 of representational flexibility.

Students of Cluster 2 for decimal numbers exhibit the same deficiencies as students of Cluster 1 for decimal numbers in treatment, recognition with the same number of decimal digits and conversion tasks. However, due to their moderate performance in recognition tasks with different number of decimal digits they belong to a higher level of representational flexibility. 


\subsection{Cluster 3}

Students in Cluster 3 of fraction addition generally perform better than the students in Clusters 1 and 2. These students exhibit high performance in the treatment tasks. They attain moderate performance in the recognition tasks of fraction addition with the same denominators and different denominator fraction additions. Their performance in the conversion tasks is low irrespective of the initial representation, symbolic or diagrammatic. This means that these students face difficulties in producing a symbolic or diagrammatic representation of a fraction addition given in a diagrammatic or symbolic form respectively. The above characteristics suggest that students in Cluster 3 are at a higher developmental level in relation to students in Cluster 2 who perform well only in the treatment tasks. Thus, the students in Cluster 3 belong to the third level of the representational flexibility hierarchy.

Students in Cluster 3 for decimal numbers exhibit high performance in the treatment tasks, conversion from a symbolic to a diagrammatic expression and the reverse and recognition tasks with the similar digits. However, they are not competent in recognizing whether a circle, a rectangle or a number line model represents a given symbolic expression of decimal number addition with different number of decimal digits. Their performance in these tasks is similar with the performance of students who belong to Cluster 1 for decimal numbers.

\subsection{Cluster 4}

Cluster 4 in fraction addition involves high achievers in most of the tasks. Due to their greater success in dealing with transformation tasks in relation to the students of the previous clusters, these students belong to the highest developmental level of representational flexibility that was identified in this study, Level 4. They demonstrate high performance in recognition of fraction additions with the same denominators and different denominators and treatment tasks. Nevertheless, dissociation between the conversions from and towards symbolic expressions is found in their performance. Even though they exhibit high performance in conversion tasks from symbolic to diagrammatic representation, they perform moderately in the conversion tasks from a diagram to a symbolic expression. Cluster 4 in decimal numbers involves high achievers, as in the case of fractions. The sharp dissociation 
though in their performance between the conversions from and towards symbolic expressions was not found as in the case of Cluster 4 in fraction addition.

According to the results in Tables 5 and 6, students in all clusters exhibit lower performance in recognition and conversion fraction addition tasks with the same denominators that involve number line in relation with those that involve bi-dimensional diagrams. The same occurs in recognition and conversion tasks in decimals.

\subsection{The relation between hierarchical levels and students' age}

Table 7 presents the frequency distribution of Grade 5 to 8 school students, at the four developmental levels of representational flexibility in fraction and decimal number addition. A chi-square test reveals that there are significant differences between the four age groups regarding their distribution within the four representational flexibility levels in fraction $\left[\left(\mathrm{x}^{2}\right.\right.$ $(9)=73.65, \mathrm{p}<0.01]$.

Delving further into the correspondence of the hierarchical levels with school grades, standardized residuals are used to find out which ones have major influence on the chi-square test statistic. In these cases the absolute value of the residual should be greater than 2.00 . According to this analysis, within the highest level of representational flexibility in fractions, eighth graders possess the most significant proportion among the students of all grades, while fifth graders are significantly underrepresented. Within the third developmental level of representational flexibility seventh graders are significantly underrepresented. The most significant proportion of students in the second level of representational flexibility is possessed by the youngest students of the study, the fifth graders. At the lowest level of the representational flexibility, the majority of the students are seventh graders, whereas eighth graders are significantly underrepresented. 
Table 7- Frequency Distribution of Hierarchical Levels by Grade in Fraction and Decimal Number Addition (Standardized residuals appear in parentheses below group frequencies)

\begin{tabular}{|c|c|c|c|c|c|c|}
\hline Levels & $\begin{array}{l}\text { Rational } \\
\text { Number }\end{array}$ & $\begin{array}{l}\text { Grade } 5 \\
(f)\end{array}$ & $\begin{array}{l}\text { Grade } 6 \\
(f)\end{array}$ & $\begin{array}{l}\text { Grade } 7 \\
(f)\end{array}$ & $\begin{array}{l}\text { Grade } 8 \\
(f)\end{array}$ & $\bar{N}$ \\
\hline \multirow[t]{2}{*}{ Level 1} & Fractions & $\begin{array}{l}58 \\
(-0.3)\end{array}$ & $\begin{array}{l}47 \\
(-1.8)\end{array}$ & $\begin{array}{l}99 \\
(5.1)\end{array}$ & $\begin{array}{l}45 \\
(-2.8)\end{array}$ & 249 \\
\hline & Decimals & $\begin{array}{l}164 \\
(3.1)\end{array}$ & $\begin{array}{l}116 \\
(-1.2)\end{array}$ & $\begin{array}{l}116 \\
(-0.9)\end{array}$ & $\begin{array}{l}134 \\
(-0.9)\end{array}$ & 530 \\
\hline \multirow[t]{2}{*}{ Level 2} & Fractions & $\begin{array}{l}105 \\
(2.7)\end{array}$ & $\begin{array}{l}75 \\
(-0.6)\end{array}$ & $\begin{array}{l}68 \\
(-1.2)\end{array}$ & $\begin{array}{l}83 \\
(-0.8)\end{array}$ & 331 \\
\hline & Decimals & $\begin{array}{l}116 \\
(0.2)\end{array}$ & $\begin{array}{l}96 \\
(-1.7)\end{array}$ & $\begin{array}{l}143 \\
(2.9)\end{array}$ & $\begin{array}{l}115 \\
(-1.2)\end{array}$ & 522 \\
\hline \multirow[t]{2}{*}{ Level 3} & Fractions & $\begin{array}{l}148 \\
(1.5)\end{array}$ & $\begin{array}{l}141 \\
(0.9)\end{array}$ & $\begin{array}{l}105 \\
(-2.1)\end{array}$ & $\begin{array}{l}144 \\
(-0.3)\end{array}$ & 538 \\
\hline & Decimals & $\begin{array}{l}47 \\
(0.5)\end{array}$ & $\begin{array}{l}46 \\
(0.4)\end{array}$ & $\begin{array}{l}32 \\
(-1.6)\end{array}$ & $\begin{array}{l}54 \\
(0.7)\end{array}$ & 179 \\
\hline \multirow[t]{2}{*}{ Level 4} & Fractions & $\begin{array}{l}103 \\
(-3.3)\end{array}$ & $\begin{array}{l}152 \\
(0.8)\end{array}$ & $\begin{array}{l}134 \\
(-0.4)\end{array}$ & $\begin{array}{l}194 \\
(2.7)\end{array}$ & 583 \\
\hline & Decimals & $\begin{array}{l}87 \\
(-3.6)\end{array}$ & $\begin{array}{l}157 \\
(2.6)\end{array}$ & $\begin{array}{l}115 \\
(-0.9)\end{array}$ & $\begin{array}{l}163 \\
(1.7)\end{array}$ & 470 \\
\hline $\mathrm{N}$ & & 414 & 415 & 406 & 466 & 1701 \\
\hline
\end{tabular}

The chi-square test reveals that there are significant differences between the four age groups regarding their distribution in the four representational flexibility levels in decimal number addition $\left[\left(\mathrm{x}^{2}(9)=52.25, \mathrm{p}<0.01\right]\right.$, as well. According to standardized residuals, within the highest level of representational flexibility in decimal number addition, sixth graders possess the most significant proportion among the students of all grades, while fifth graders are significantly underrepresented. Within the third developmental level of representational flexibility all the grades are almost equally presented. The most significant proportion of students in the second level of representational flexibility consists of the seventh graders. At the lowest level of the representational flexibility, the majority of the students are the younger students, the fifth graders.

The results indicate that students of the same educational institution moved to higher levels of representational flexibility in fraction and decimal addition with school grade, that is, from fifth to sixth grade of primary school or from seventh to eighth grade of secondary school, respectively. As far as decimals are concerned sixth graders' representational flexibility is at a higher level compared to the flexibility of the fifth graders and secondary school students. Furthermore, eighth graders' representational flexibility in fraction addition is at a higher level compared to the flexibility of the students in primary school. This is not however the case for seventh graders. Thus, students' representational flexibility does not improve from sixth grade to seventh grade, which is the transition period from one educational institution to the other. 


\section{A didactical implication using formative assessment}

In this section, we will focus our discussion on an implication for fostering student representational flexibility. We take as an example a task ${ }^{1}$ which involves different types of competences when using representations and discuss how these competences can be strengthened in respect to various formative assessment techniques. It is worth mentioning that this is a proposal which is not experienced and could be a subject for a future research study.

Kieran's teacher wrote the following problem on the board: $\frac{1}{2}+\frac{1}{3}=$.

What is the answer to this addition? Use words, pictures and numbers to explain your thinking.

Kieran completed the problem showing his thinking with words, pictures, and numbers in the following way:

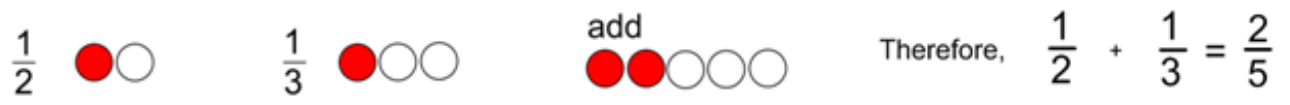

Add tops and bottoms

What do you think of Kieran's answer? Is he correct? Justify your thinking.

Figure 1 - The proposed task

\subsection{Analysis of the task in relation to representational transformations}

Step 1 - Conversion from symbolic to diagrammatic representation: Students produce the diagrammatic representations of the fractions given in a symbolic form.

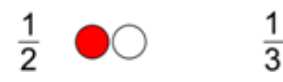

Step 2 - Treatment of diagrammatic representations: Students use the two diagrammatic representations of fractions and add them.

\section{add}

Step 3- Conversion from diagrammatic representation (treatment procedure in step 2) to symbolic representation: Students express the fraction addition displayed in the diagrammatic representation using a symbolic expression.

$$
\text { Therefore, } \frac{1}{2}+\frac{1}{3}=\frac{2}{5}
$$

\subsection{Analysis of the task in relation to formative assessment}

\footnotetext{
${ }^{1}$ The task is found from the Georgia Mathematics Educator Forum website (https://ccgpsmathematicsk5.wikispaces.com).
} 
This task gives the students the opportunity for peer-assessment byanalyzing mistakes in a solution procedure provided by an imaginary student. Students may be organized to work in small groups in order to analyse this work sample. In this way, they have the chance to analyse the mistakes in collaboration, to express their thinking about these mistakes and to provide peer-feedback to each other about their ideas for them. Guiding questions may facilitate students to estimate the sum: Compare the value of addends in relation to $\frac{1}{2}$, then look at the value of sum (in relation to $\frac{1}{2}$ ) and think whether the given answer is possible (is $\frac{2}{5}$ less than $\frac{1}{2}$ ?). The teacher should also try to guide students towards the conversion from symbolic to diagrammatic representations, asking them to decide whether the representations provided by the imaginary student are suitable (Is $\frac{1}{2}$ represented correctly in Kieran's picture? Is $\frac{1}{3}$ represented correctly in Kieran's picture?). The teacher may also prompt students to use other models or representations in order to estimate the sum: Can you represent these fractions on a number line/ rectangular area diagram? Show this addition using fraction bars. These questions guide students to understand both the way the imaginary student work (peerassessment), but to assess as well their own understanding at the end of the activity (selfassessment). The students may also assess the quality of Math's work by using a rubric. As we focus on particular aspects of representational flexibility, the rubric shall guide the students to assess this imaginary student's sample work in terms of the representations that are involved in this solution and the competences (treatment and conversions) that are necessary during the elaboration of these representations. At the end, the students can use the rubric again for self-assessment.

\section{Discussion}

A main contribution of our study is the identification of hierarchical levels in representational flexibility in fraction and decimal number addition. In particular, our findings suggest that there are at least four developmental levels of students. We suggest that these developmental levels correspond to levels that compose MWS in fraction and decimal number addition. Thus, we assume that the genesis of the semiotic axis in rational numbers is not an automatic but a long process of developmental steps, that could be referred to as MWS1, 
MWS2, MWS3, MWS4 (final). At MWS1, students do not yet develop their representational transformation competences in fraction and decimal number addition. At MWS2 students develop the ability to carry out treatments of fraction and decimal addition in the symbolic system of representation. At MWS3 students are able to carry out symbolic treatments, but also to recognize the diagrammatic representations of fraction and decimal additions that are given in symbolic form. At MWS4 students are able to handle symbolic treatments but also to carry out transformations from symbolic representations of fraction and decimal addition to diagrams either by recognizing the appropriate diagram(s) or by constructing them. However, they encounter difficulties though in converting additions from diagrammatic representations towards symbolic expressions.

However, differences are also revealed between the two symbolic registers of rational numbers. An interesting phenomenon that our findings reveal in decimals was the dissociation between the conversions from and towards symbolic expressions in lower levels. This type of compartmentalized way of thinking is found, though even at the highest level of representational flexibility in fraction addition. The great majority of the students, even the students belonging to the MWS4, find the conversions of fraction additions from diagrammatic representation to symbolic expression much more difficult than the inverse conversions. Although the two types of conversion tasks refer to the same concept, they seem to require different or more complex types of cognitive processes. Thus, changing representations in a mathematical domain is not a reversible process; it can be transparent or congruent in one direction and not transparent in the other (DUVAL, 2006). A high level of representational flexibility in fraction addition, presupposes success in both types of tasks, which is, moving back and forth from the symbolic to the diagrammatic representation. Lack of this kind of flexibility among the students of this study indicates that they do not sufficiently understand the common concept denoted by both the symbolic expression and the diagrammatic representation (DUVAL, 2006).

Difficulties are also indicated in recognizing the diagrammatic representations of decimal number additions with different number of decimal digits that are given in symbolic form even at a high level of representational flexibility (MWS3). However, difficulties with different denominator fraction addition recognition are indicated only at the lower levels of representational flexibility in fraction addition. This may be explained by taking into account the fact that in recognizing the diagrammatic representations of decimal number additions 
with different number of decimal digits, the transitional step of converting each decimal number to fraction with fixed denominator in order to be solved is required.

Based on these findings, there seems to be a regular and systematic increase in the sophistication from one level to another. Thus, these hierarchical levels and specifically the different competences that they encompass can be of practical use because they may support the progressive organization of learning activities on fraction and decimal number addition by difficulty level, which could help students with various abilities to develop their representational flexibility within the particular domain. In fact, the choice and the organization of the tasks given by the teacher to the students are essential in the constitution of the adequate MWS, so that the teacher gives an opportunity to the students to solve in an appropriate manner the activities offered (KUZNIAK; RICHARD, 2014). As Fandiño Pinilla (2007) pointed out to in order to handle registers and choose the distinguishing features of the concept the student must treat and convert, is not learnt automatically. This learning is a result of a process of explicit teaching in which the teacher must render the student co-responsible. The teacher is able to jump from one register to another without problems, because he has already conceptualized: the student still does not so, the student follows at the level of semiotic representatives, but not of meanings (FANDIÑO PINILLA, 2007).

There is no thought of a clear and stable correspondence between the developmental levels of representational flexibility and school grades. Students within the same educational institution appear to move to higher levels of representational flexibility with school grade, but there is a lack of improvement in the transition period, from the last grade of primary school (Grade 6) to the first grade of secondary school (Grade 7) in fraction and decimal number addition. These results move a step forward Gagatsis \& Deliyianni's (2014) results, that indicated interesting variations in student performance regarding the conversion ability having diagrammatic and symbolic representation as the source and target representation respectively, and vice versa, and verbal and diagrammatic problem-solving ability across these age groups. Our findings revealed that the students' performance improved within the same educational institution (primary school, secondary school). However, a hiatus in performance progress is indicated when the students move to secondary school.

The use and the meaning of representations in teaching and learning of fraction and decimal number addition depend on different paradigms: a multiple representations approach (paradigm I) or a symbolic approach (paradigm II). In line with previous results (GAGATSIS; DELIYIANNI, 2014), it seems that the MWS of the primary school students (personal) and 
teachers (appropriate) are based on the same paradigm (paradigm I) regarding fraction and decimal number addition. Within the MWS of both, students and teachers, the component of the epistemological level related to semiotic representations is conceived and approached in the same way. In particular, the mathematical work of both teachers and students is based on the use not only of symbolic representations, but also of diagrammatic and verbal representations and their interrelations. However, the reference MWS which is aimed to by secondary schools concerning the concept of fraction and decimal number addition has not been successfully transformed into an appropriate MWS, as it does not allow its successful implementation in the classroom where every student works within his/her personal MWS. Secondary school students at this early stage (Grade 7) need to use not only symbolic representations, but also diagrammatic and verbal representations and their coordination in order to solve fraction and decimal number addition tasks (paradigm I). Schools and teachers, however, promote a more abstract and symbolic approach to the representation and learning of fractions and decimals (paradigm II). Therefore, when the students encounter tasks that require flexible manipulation of representations in fraction and decimal number addition, they face difficulties. The emphasis given in teaching on the symbolic writings is an element of the paradigm that is found in Block, Nikolantonakis and Vivier's (2012) study as well. Block et al. (2012) indicated also the fact that flexibility between registers is important for the solution of non-routine tasks.

Students' training towards a reflective and flexible thinking when using representations can limit this discrepancy. This training can be incorporated in the use of formative assessment practices that can facilitate the use of representations and enhance their flexible manipulation from one system of representation to another. The use of specific formative assessment practices can guide the students' use of representations to produce a solution, reflect on a solution and trace common mistakes and misconceptions and overcoming them with self-guided work.

In fact, a powerful influence of formative assessment on achievement is the meaningful feedback from students as to what they know and where they make errors or have misconceptions (HATTIE, 2009). Exploiting student errors in a formative way, especially when converting fraction and decimal additions from diagrammatic representations to symbolic expressions, having students assess themselves but also their peers when using different forms of representation and models and providing formative feedback to each other about how they could improve their work when constructing or manipulating representations 
are among practices that have the possibility to bring students' thinking towards this direction. Good feedback practice facilitates the development of self-assessment in learning (MICHAEL-CHRYSANTHOU; GAGATSIS, 2014), encourages teacher and peer dialogue about learning, helps to clarify what good performance is, provides opportunities to close the gap between current and desired performance, delivers high quality information to students about their learning, encourages positive motivational beliefs and self-esteem and provides information to teachers that can be used to help shape the teaching. It is, thus, important to turn the attention towards gaining feedback from students about their difficulties and misconceptions when recognizing, treating or conversing between representations from one register to another and not only providing them feedback on whether they used representations in the expected way. Consequently, through this reflection students' selfmonitoring abilities can be strengthened, turning the students to self-regulated and independent learners and flexible users of multiple representations, not only in rational numbers, but also in other mathematical concepts that involve the use of a variety of representations, such as algebraic and geometrical thinking.

The separation and the correspondence between fraction and decimal tasks facilitate us to begin with the identification of students' response profiles for representational flexibility in fraction and decimal addition and compare them. In the future, tasks that involve a coordination of registers using both fraction and decimal number additions (e.g., 0,23 + 1/2) should be used in order to confirm MWS levels. Furthermore, the extent to which the developmental levels of representational flexibility that are identified in this study apply in the learning of other concepts or in different age ranges could be of great theoretical and practical interest.

\section{References}

BARNETT-CLARKE, C. et al. Developing essential understanding of rational number: grades 3 5. Reston: National Council of Teachers of Mathematics, 2010.

BLOCK, D., NIKOLANTONAKIS, K.; VIVIER, L. Registre et praxis numérique en fin de première année de primaire. Annales de Didactiques et de Sciences Cognitives, Strasbourg, v. 17, p. 59-86, 2012.

BOULET, G. Didactical implications of children's difficulties in learning the fraction concept. Focus on Learning Problems in Mathematics, Framingham, v.20, n. 4, p.19-34, jan. 1998.

CHARALAMBOUS, C.; PITTA-PANTAZI, D. Drawing on a theoretical model to study students' understanding of fractions. Educational Studies in Mathematics, Netherlands, v. 64, n.3, p.293-316, mar. 2007. 
DELIYIANNI, E. et al.. Representational flexibility and problem-solving ability in fraction and decimal number addition: a structural model. International Journal of Science and Mathematics, Netherlands, p. 1-21 (first online), mar. 2015.

DUVAL, R. A cognitive analysis of problems of comprehension in learning of mathematics. Educational Studies in Mathematics, Netherlands, v. 61, p. 103- 131, feb. 2006.

FANDINO PINILLA M. I. Fractions: conceptual and didactic aspects. Acta Didactica Universitatis Comenianae, Bratislava, v. 7, p. 23-45, 2007.

GAGATSIS, A.; DELIYIANNI, E.. Mathematical working space relations with conversions between representations and problem solving in fraction addition. Revista Latinoamericana de Investigación en Matemática Educativa, Cinvestav, v. 17, n. 4-I, p. 249-266, dic. 2014.

HATTIE, K. Visible learning: a synthesis of over 800 meta-analyses relating to achievement. New York: Routledge, 2009.

IRWIN, K., C. Using everyday knowledge of decimals to enhance understanding. Journal for Research in Mathematics Education, Reston, v. 32, n. 4, p. 399-420, jul. 2001.

IUCULANO, T.; BUTTERWORTH, B. Understanding the real value of fractions and decimals. The Quarterly Journal of Experimental Psychology, London, v. 64, n. 11, p. 2088-2098, sep. 2011.

KUZNIAK, A. L' espace de travail mathématique et ses genèses. Annales de didactique et de sciences cognitives, Strasbourg, v. 16, p. 9-24, 2011.

KUZNIAK, A. Understanding the nature of the geometric work through its development and its transformations. In: SUNG, J. C. (Ed.), selected regular lectures from the 12th international congress on mathematical education. Switzerland: Springer International Publishing, 2015, p. 1-15.

KUZNIAK, A.; RICHARD, P. R. Spaces for Mathematical Work. Viewpoints and perspectives, Revista Latinoamericana de Investigación en Matemática Educativa, v. 17, n. 4-I, p. 17-28, dic. 2014.

LAMON, S. Presenting and representing from fractions to rational numbers. In: CUOCO A. A.; CURCIO F. R. (Ed.). The role of representation in school mathematics.Boston: NCTM, 2001. p.146-165.

LESH, R., POST, T.; BEHR, M. Representations and translations among representations in mathematics learning and problem solving. In: JANVIER C. (Ed.). Problems of representation in the teaching and learning of mathematics.Hillsdale, N.J.: Lawrence Erlbaum Associates, 1987. P.33-40.

MICHAEL-CHRYSANTHOU, P.; GAGATSIS, A. Students' beliefs for formative assessment in mathematics teaching and learning, Nicosia, EAPRIL Conference Proceedings, v. 1, p. 178-193, nov. 2014.

RODITI, E. Aider les élèves à apprendre à comparer des nombres décimaux. Nouveaux cahiers de la recherche en éducation, Paris, v. 10, n. 1, p. 5-26, 2007.

Submetido em Julho de 2015. Aprovado em Setembro de 2015. 


\section{Appendix}

1. Recognition tasks

Circle the diagram or the diagrams whose shaded part corresponds to $0.03+0.01$

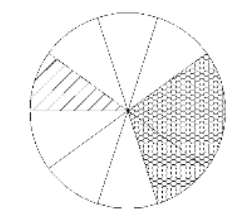

$(\operatorname{Red} 4)$

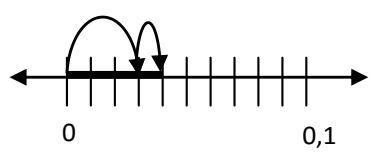

$(\operatorname{Red} 5)$

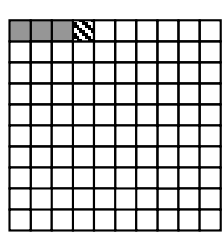

(Red6)

Circle the diagram or the diagrams whose shaded part corresponds to $\frac{2}{3}+\frac{1}{4}$

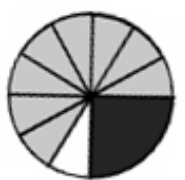

(Ref5)

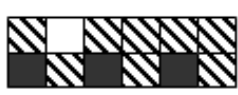

(Ref6)

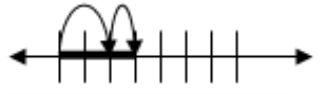

01234567

(Ref7)

2. Symbolic treatment tasks

$$
\frac{1}{6}+\frac{4}{12}=\ldots
$$

3. Conversion tasks

Illustrate the following symbolic expression on the diagram:

$$
0.05+0.04=\ldots
$$

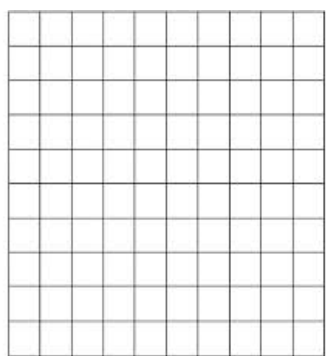

$(\operatorname{Cod} 16)$

Write the fraction addition symbolic expression that corresponds to the shaded part of the following diagram:

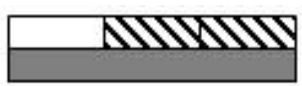

(Cof17) 